\title{
V EPEA - Encontro de Pesquisa em Educação Ambiental
}

\section{Entrevista ${ }^{1}$ Professor Renato Ortiz}

\section{Marco Antonio de Almeida}

Entrevistaremos o professor Renato Ortiz, que proferiu a palestra de abertura no V encontro do EPEA com o tema Ciências Sociais e o Mundo Contemporâneo. O professor Renato Ortiz é docente da UNICAMP, com formação em ciências sociais na França, onde viveu muitos anos, e é um dos introdutores no Brasil da discussão sobre a globalização, tema de seus últimos livros. Em continuidade aos temas abordados pelo professor Renato na sua palestra, inicio com a seguinte pergunta: você falou da constituição do campo das ciências sociais, que se construiu sob o signo de um paradoxo, de um lado a necessidade de constituição de um pensamento autônomo e de outro lado, duas outras questões, as demandas utilitaristas que eram feitas a esse campo e a própria impossibilidade dele se constituir num monopólio do saber. Gostaria que você retomasse esse ponto e o explorasse um pouco mais.

\section{Renato Ortiz}

As Ciências Sociais nascem no final do século XIX e estabelecem um determinado padrão de conhecimento que se torna constitutivo do seu modo de ser. Dito de outra forma, algumas questões metodológicas que elas enfrentam são permanentes, e não serão "superadas" com o tempo. Esse dilema, que estou nomeando como constitutivo de sua natureza, diz respeito à constituição de fronteiras. Todo pensamento, para existir, requer a existência de fronteiras. Sem isso, a reflexão sobre a sociedade simplesmente inexiste. Entretanto, simultaneamente, essas fronteiras, que eu tenho o hábito de dizer, são porosas, são pressionadas por um conjunto de demandas que lhes são externas. Uma maneira de entender este dilema (e não falo de paradoxo) é através da idéia de utilidade, muito debatida ao longo do XIX. Utilidade que reveste-se de várias formas e se diversifica em função dos objetivos a serem alcançados: educacionais, profissionais, políticos, religiosos. A tensão se instaura porque as Ciências Sociais constituem um território específico (objeto sociológico, método, técnicas de pesquisa, conceitos) mas são recorrentemente desafiadas pelas demandas de "utilidade". Antes do final do XIX esta tensão inexiste: Marx, Comte, Fourier, "fazem ciência" e não vêem nenhuma contradição em colocar

1 Entrevista a Marco A. de Almeida, Rosa M. F. Cavalari e Clarice Sumi Kawasaki; transcrita por Ariane Di Tullio e editada por Marco A. de Almeida. 
em prática o que eles descobrem, em prol de uma sociedade melhor. Os autores do final do século (Durkheim, Weber) encontram-se noutra posição: eles percebem as contradições entre um pensamento que se quer "científico" e as exigências de outras esferas da sociedade (por exemplo, a educação para Durkheim ou a política para Weber). Somos herdeiros desta tensão insuperável. Talvez por isso eu aprecie a ideia de vigilância epistemológica. A vigilância é necessária porque as fronteiras são porosas, imprecisas, elas não estão nunca garantidas de antemão.

\section{Marco Antonio de Almeida}

Precisa vigiar as fronteiras, está certo.

\section{Renato Ortiz}

Exatamente.

\section{Marco Antonio de Almeida}

Então, fazendo um gancho com esse aspecto e relacionando ao tema aqui do encontro, o campo da educação ambiental ou a questão da educação ambiental, nesse sentido, ele também teria uma demanda de utilidade, uma demanda utilitarista, não é? E, por outro lado, existiria também a necessidade dos pesquisadores nessa área de constituir um pensamento autônomo. Tentando fazer um paralelo com as ciências sociais, você acha que esse campo da educação ambiental constituiria uma nova disciplina científica ou um campo de conhecimento para o qual se encaminhariam várias disciplinas? Como você vê isso?

\section{Renato Ortiz}

Não creio que seria uma nova disciplina científica. No sentido de possuir um fundamento teórico, uma metodologia, uma epistemologia específica. Pareceme difícil, tomando tais exigências como referência, criar novas disciplinas científicas (digo isso no sentido mais genérico). No contexto atual já existe uma herança disciplinar que foi sendo acumulada ao longo do tempo; pode ser que em algumas áreas, se criem disciplinas ainda não conhecidas. É possível. No entanto, retornando a idéia de tensão da qual falei anteriormente, é importante compreender que a estruturação do campo científico não se origina exclusivamente das demandas externas, ou seja, do mundo da utilidade. Isso nos leva algumas vezes a formular alguns falsos problemas. Dou um exemplo que conheci de perto quando estudava a problemática da comunicação. Nos anos 60, algumas pessoas imaginaram que seria possível existir uma teoria da informação 
capaz de dar conta de todo e qualquer fenômeno de comunicação. Muito se escreveu sobre isso. Haveria um objeto específico, uma teoria que o compreenderia, e claro, uma metodologia que o apreenderia na sua inteireza. A comunicação, fenômeno universal, constituiria a base de um novo campo disciplinar. É claro que isso não deu certo. Essas ambições teóricas simplesmente caíram no esquecimento. Não quero dizer que tudo o que se fez foi inútil. Pelo contrário, o interesse por novos objetos foi capaz de orientar o olhar dos pesquisadores para um horizonte que lhes era desconhecido (apesar das ilusões contidas na idéia de uma "teoria da informação"). Talvez o mesmo ocorra atualmente em algumas áreas: por exemplo, os estudos culturais. Não creio que eles constituam uma "nova disciplina", tampouco me parece viável falar de uma "teoria da cultura"; porém, não diria que esses estudos não tenham nenhuma virtude. Eles são capazes de trabalhar um conjunto de questões e tem influência, inclusive, em outras disciplinas já estabelecidas, como a Sociologia ou a Antropologia.

\section{Marco Antonio de Almeida}

No limite, poderíamos pensar a própria educação.

\section{Renato Ortiz}

No limite, a própria educação. Penso que às vezes no debate contemporâneo existe uma certa ansiedade quando se fala de esferas do saber, existe...

\section{Marco Antonio de Almeida}

... A necessidade de conferir uma legitimidade...

\section{Renato Ortiz}

... De conferir um fundamento, uma legitimidade epistemológica que, na minha opinião, dificilmente se realizaria. $\mathrm{Na}$ verdade, essas questões controversas, permeiam as próprias disciplinas já estabelecidas. Quem faz ciências sociais sabe disso.

\section{Marco Antonio de Almeida}

Certo. Uma coisa que você mencionou também na sua fala, Renato, foi a questão de um ponto que te parecia interessante, com relação ao movimento ambiental, que ele remete a um espaço global, um espaço mais amplo que seria a própria Terra. Então, nesse sentido, ele aponta para uma nova totalidade, pelo menos em termos de objeto, não é? Esta é uma preocupação para a gente pensar. 
Eu te perguntaria, pensando a partir desse novo espaço global, desse objeto que se constitui nesse campo de problematização - como a gente está chamando aqui -, como é que fica a questão das identidades? Porque aí remeteríamos também àquilo que você também mencionou, dos espaços de desterritorialização e reterritorialização.

\section{Renato Ortiz}

As pessoas que trabalham com meio ambiente sempre tiveram uma sensibilidade em relação ao debate da globalização. Essa sensibilidade provém do próprio objeto, ou melhor, da proposta de reflexão que elas pretendem desenvolver. Ou seja, na medida em que se toma um referente único, a Terra, o planeta, independente da forma como o pensamento se faz, a área no qual ele se enraiza trabalha a partir de algo cuja dimensão é global. Isso cria uma sensibilidade entre os praticantes dessa esfera de saber em relação, digamos assim, às questões planetárias. Isso é distinto, por exemplo, entre os cientistas políticos. A comparação é sugestiva. Os cientistas políticos estão muito marcados pela presença do Estado-Nação. Este é o lugar no qual preferencialmente a política se realiza. Eles têm, portanto, uma certa dificuldade em tratar a problemática da globalização; suas categorias de análise encontram-se amarradas à uma territorialidade "regional". Claro, pode-se dizer que muitas vezes as pessoas vinculadas ao meio ambiente têm um certo exagero em considerar " $\mathrm{A}$ Terra", como um todo singular, quando na verdade existe uma diversidade, uma série de conflitos no interior desta "Terra". Mas do ponto de vista da percepção do fenômeno, parece-me positivo que eles se voltem para questões que transcendam os limites das fronteiras geográficas.

A questão das identidades na situação de globalização é de outra natureza; não a considerei durante minha conferência, embora, como você sabe, escrevi bastante sobre o assunto. Como eu poderia dizer algo relevante, e de maneira concisa, sobre o tema? Bem, primeiro é preciso lembrar: a identidade nunca é uma essência, uma coisa em si. Embora exista uma tradição culturalista em antropologia que busca captar sua essência. O brasileiro é "festivo", o japonês "trabalhador", o americano "democrático"; a partir deste tipo de argumentação torna-se, inclusive possível, comparar tais identidades. Na verdade, não existe o brasileiro, o japonês. O artigo "o", utilizado no singular, está mal empregado na frase. Existe uma construção histórica, simbólica, de uma identidade que se manifesta e se transforma em diferentes contextos. A identidade é uma construção simbólica que faz em relação a um referente. $\mathrm{O}$ referente pode ser a nação, como no exemplo anterior: Brasil, Japão, Estados Unidos. Mas ele pode variar: sexo, grupos indígenas ou étnicos, negros. Existe, 
portanto, uma disputa pelas identidades, elas não são nunca única, singulares. Sobretudo na situação de globalização. Por isso é ilusória imaginarmos a existência de uma identidade global.

Como que fica a problemática das identidades no mundo globalizado? Algumas pistas que podem ser exploradas. Tenho o costume de utilizar uma idéia de Weber, quando ele discute o monopólio das religiões. Por exemplo, ao se afirmar que os católicos na Idade Média detinham o monopólio da religião, isso não significa que não existissem outras religiosidades, apenas que os católicos predominam, possuem a hegemonia no campo religioso. Eu diria, parafraseando Weber, que durante construção da modernidade, o Estado-Nação possuía o monopólio da definição das identidades. Ou seja, o tema de identidade nacional é central (no Brasil, como em outros países). Hoje, na situação de globalização, o Estado-Nação perdeu tal monopólio de definição. Dito de outra forma: as identidades são construídas por "baixo" e por "cima". Por baixo, eu me refiro às identidades regionais (no Brasil, a baianidade); além de outros processos identitários que atravessam as sociedades atuais: grupos feministas, reivindicações de negros e indígenas ... Mas também é possível termos agora referentes transnacionais, portanto, construções de identidades vinculadas à modernidade-mundo. Por exemplo, a juventude de uma certa classe média que frequenta os shopping centers; ou, ainda, o hip-hop como um referente transnacional, reapropriado por grupos juvenis vivendo na periferia de grandes cidades. Existe, portanto uma multiplicação das possibilidades de construção das identidades, o "monopólio"anterior se cindiu.

\section{Marco Antonio de Almeida}

Seguindo essa sua linha de raciocínio, eu conectaria aqui uma questão também levantada por você na sua conferência, que é a do eurocentrismo. Em que medida ele vai se diluindo, esse eurocentrismo que foi fundamental na constituição das Ciências Sociais, desse cânone clássico das Ciências Sociais, em alguma medida ele vai sendo erodido por esse processo de globalização ...

\section{Renato Ortiz}

Curioso, o tema do eurocentrismo desfruta no Brasil de uma posição ambigua. Somos politicamente corretos e evitamos a todo custo as questões espinhosas. Até certo ponto isso encerra uma certa dubiedade, não é? Afinal as ciências sociais, para se afirmarem enquanto, brasileiras, devem se contrapor a algo que lhes é exterior. Entretanto, pelo fato deste exterior ser o espelho no qual elas se miram, ele deixa de ser problematizado. Na Europa e nos Estados Unidos (costumávamos dizer, nos paises centrais) as coisas são diferentes. A 
critica política ao eurocentrismo (colonialismo, imperialismo) assim como teórica, tornou-se corriqueira. No contexto de um mundo globalizado, a produção conceitual, já não mais obedece as hierarquias tradicionais sacramentadas no mundo acadêmico.

$\mathrm{Na}$ nova introdução ao meu livro Mundialização e Cultura, que será republicado em breve, assinalo uma questão interessante em relação ao lugar dos intelectuais na esfera do pensamento. Procurei estabelecer um contraste entre a América Latina e o Brasil no final do século XIX e a temática da globalização. No final do XIX, a sociologia nasce pensando a cidade, a fábrica, o centro urbano, a divisão do trabalho, ou seja, aquilo que é visto como moderno. Mas, na América Latina, o que temos? Nada disso. Nossa realidade é outra: zona rural, grupos indígenas, mestiçagem, ausência de centros urbanos, defasagem em relação à revolução industrial; portanto, na América Latina, as ciências sociais tematizam a ausência. Essa é a nossa tradição. A presença da modernidade encontrava-se "lá fora" (na Europa). Nossos intelectuais encontravam-se numa posição desconfortável em relação aos europeus ou norte-americanos. Eles não viviam a materialidade dessa modernidade ausente, podiam apenas, mimetizá-la. Os modernistas dos anos 20 cantavam o bonde, a luz elétrica, o avião, o cinema, numa sociedade na qual isso era mais imaginação do que realidade. Eles possuíam a vivência de um modernismo sem modernidade. Com a globalização é diferente. Em São Paulo, Tóquio, Nova York, Paris, Buenos Aires ou Cidade do México, somos atravessados pelo mesmo processo. Certamente sua realização histórica é diferente na Cidade do México ou em Nova York, existe, porém, uma totalidade que envolve esses diferentes lugares; todos fazem parte da modernidade-mundo. Isso significa que é possível pensar o processo a partir de qualquer um desses pontos. Essa é a grande diferença em relação à nossa condição anterior; já não é mais necessário estar no "centro" para se pensar a contemporaneidade. Nossa vivência deixa de ser apenas "nacional" ou "local". Por isso os europeus perderam o monopólio das explicações que acreditavam ser universais.

\section{Marco Antonio de Almeida}

Nesse sentido, a educação ambiental que me parece ter um forte movimento, uma forte dinâmica, de ir ao encontro dos saberes tradicionais, saberes sobre a natureza, pode ser vista como um agente potencializador desse descentramento do conhecimento?

\section{Renato Ortiz}

Certamente, mas o descentramento se faz em todas as esferas, ele é parte do "espírito de uma época". Hoje, dificilmente poderíamos escrever a partir de 
uma visão linear do tempo. A ideologia do progresso, característica do otimismo do século XIX, feneceu. $\mathrm{Na}$ situação de globalização a metáfora do espaço sobrepõe-se a do tempo. Os países subalternos já não mais imaginam uma linha do tempo na qual, um dia, seriam modernos (civilizados). Também os chamados paises centrais deixaram de ser o modelo no qual nossa imagem se refletiria de forma ideal. A questão é espacial: o planeta é único, nele encontram-se paises, que por sua história, vinculam-se uns aos outros por vários tipos de relações, inclusive hierarquizadas. Isso tem implicações no plano político e teórico. Por isso os filósofos conhecem dias amargos. Já não é mais possível falar em nome da Razão, com maiúscula, como se fazia anteriormente. Mesmo um autor como Habermas tem dificuldade em compreender o mundo atual. Sua ideia de "modernidade, um projeto inacabado" é simplesmente inviável. Ela repousava numa concepção linear do tempo histórico. O "nós" da Razão é contestado segundo a posição de cada um neste espaço globalizado. Quem mora na China irá perguntar: mas que razão é esta, quem é o "nós” que a enuncia?

\section{Marco Antonio de Almeida}

Por isso que ele (Habermas) tem que apelar para a questão da comunicação, não é? Da ação comunicativa ...

\section{Renato Ortiz}

Exatamente. O problema é como pensar este "nós", o coletivo das pessoas que habitam o mesmo planeta, sem derivarmos para uma perspectiva eurocêntrica. Por isso vivemos uma espécie de um mal-estar do universal. O tempo do século XXI é global, mas sua espacialidade aponta para as diferenças, as identidades diversas que o constituem.

\section{Marco Antonio de Almeida}

E uma pergunta, retomando outro ponto, é que a questão do meio ambiente, em alguma medida, nuançou uma oposição clássica no século XIX que seria a da natureza versus cultura ou natureza versus tecnologia. Então, como você vê isso hoje num mundo que é paradoxalmente identificado como uma sociedade da informação, uma sociedade da comunicação, ou seja, remete para uma questão tecnológica e, ao mesmo tempo, desenvolve essa consciência ambiental, essa consciência da natureza, dos recursos finitos?

\section{Renato Ortiz}

Não sou um especialista, mas tenho a impressão que em certa medida, a consciência ambiental caminha ao lado dos avanços tecnológicos. Há uma 
relação entre o progresso da técnica e a desilusão em relação ao destino da natureza. Não seria exagerado dizer que, pelo menos no início, parte da consciência ecológica abrigava uma tendência romântica. Pode-se criticar tal romantismo, e a literatura sobre o meio ambiente enfatiza este ponto. No entanto, é possível imaginar o romantismo, não como uma resposta correta para a solução dos problemas, mas como um sintoma das transformações recentes. Neste sentido, os avanços tecnológicos, de uma certa forma, exacerbam a consciência em relação aos temas da natureza. Talvez eu esteja sendo generoso com o romantismo dos primeiros ecologistas. Sei que do ponto de vista interpretativo ele encerra vários problemas; mas talvez a idéia de sintoma seja interessante, desde que, não a confundamos com a base da explicação das coisas.

A questão do meio ambiente também está relacionada com toda uma crítica à noção de progresso, ela aponta para a finitude do planeta. Nos séculos XVII, XVIII, durante o Iluminismo, a crença no gênero humano era inquebrantável. Nela repousava a as certezas e as esperanças da Humanidade: o homem é um ser que se aperfeiçoaria continuamente, sua luta em busca da felicidade o afastaria definitivamente das exigências da natureza. Sabemos hoje ser esta uma visão datada. Claro, não se deve pensar que a sociedade seja a continuação da natureza. Toda sociedade, de alguma maneira, implica na construção de um conjunto de símbolos que independem da realidade biológica dos homíneos. Temos a ilusão, muitas vezes por causa da pujança tecnológica, que somente nossas sociedades modernas são assim. Eu me pergunto se não seria mais correto dizer, toda sociedade encontra-se "afastada da natureza" na mesma proporção. Mas a perspectiva que possuímos hoje é mais nuançada do que a herança iluminista, na qual a cultura existia, somente, como uma luta contra a natureza. Este tipo de certeza deixava de lado questões importantes como a morte e a degeneração do corpo. Recupera-se assim uma problemática que tinha pouco espaço para se manifestar no seio de uma ideologia do progresso. Há, no entanto, alguns problemas. O perigo é retornarmos a outras concepções biologizantes, e a seus equívocos, tão caras a certas correntes de pensamento do XIX. Particularmente as explicações de tipo raciais, nas quais o caráter e o sentimento, das pessoas e dos povos, eram uma variável da biologia e da geografia. Hoje, vemos assistir uma série de interpretações do social que tomam as descobertas atuais, por exemplo o DNA, como o seu fundamento. Difunde-se assim um senso comum planetário que pouco se diferencia de seu antecessor, de alguns séculos atrás. 


\section{Marco Antonio de Almeida}

Por princípio, o senso comum sempre se comunica com a ciência, não é? 'Tenta reduzi-la a estereótipos...

\section{Renato Ortiz}

O senso comum inclusive se nutre da ciência. Basta lermos as colunas de alguns biólogos que escrevem nos jornais. Eles não estão apenas "divulgando a ciência", suas interpretações avançam sobre as relações sociais e muitas vezes as fazem derivar da realidade biológica. Não se pode esquecer que o mundo da mídia constitui um espaço importante de constituição do senso comum. Ele envolve físicos, biólogos, médicos, cientistas políticos, etc. Não tenho a ilusão cientificista de que seja possível eliminar o senso comum; sei que as ciências se fazem em domínios específicos, que de alguma forma, devem estabelecer fronteiras com o mundo da vida. Mas a sociedade tem inúmeras outras formas de criar narrativas, desde as míticas até o debate político. Não há porque ficarmos reféns de um cientificismo desfocado. Mas me espanta a certeza de certos colegas, físicos sobretudo, em decretar o certo e o errado, a partir de suas experiências de laboratório. Eles se esquecem que as teorias que professam tem uma validade restrita, aplicam-se ao laboratório, mas não fora deles.

\section{Rosa Maria Feiteiro Cavalari}

Bem professor, embora o senhor tenha dito ontem que a palavra epistemologia é uma palavra que o senhor procura evitar, que é uma palavra um pouco complicada, eu gostaria de retomar esse ponto, se possível. Muito rapidamente aqui nessa conversa, o senhor já tocou nesse assunto. A questão é em relação à possibilidade de uma epistemologia, uma epistemologia ambiental ou saber ambiental. Existem nesse campo alguns autores que afirmam essa possibilidade e até apontam alguns caminhos. O senhor disse que dificilmente haveria essa possibilidade. Eu gostaria que o senhor explicasse por que, em que sentido, há esta dificuldade na constituição duma epistemologia ambiental.

\section{Renato Ortiz}

Veja, eu apenas expressei uma opinião. Uma argumentação mais séria requereria uma fundamentação mais elaborada. Parece-me, no entanto, que muitas dessas áreas, as quais denominamos de interdisciplinares, são o resultado do cruzamento de intenções e de disciplinas diversas. Para existir uma epistemologia específica, seria necessário ocorrer uma síntese dessas diferentes intenções. A mera reunião delas não é suficiente para lhes conferir uma coerência interna, a ponto de a considerarmos como o fundamento epistêmico do 
conhecimento. Tenho dúvidas em relação a isso. Você poderia me dizer: "não, mas um dia esta síntese irá se realizar"; neste caso eu diria, mudo de opinião. Mas num primeiro momento isso me parece difícil. Como havia dito anteriormente, esta é uma discussão que acompanhei em outros setores. A tentativa de se criar paradigmas, que seriam sinônimos de uma epistemologia científica, é generalizada, e a meu ver, pouco consistente (eu até prefiro evitar o termo paradigma). Talvez eu não seja tão cientificista a ponto de considerar que toda área de conhecimento necessitaria de uma epistemologia própria. Não possuo este tipo de ansiedade teórica. Mas sei que muitos autores, em determinadas áreas, cultivam essa idéia. Eu me lembro que nos anos 60 as pessoas liam autores como Wiener ou Abraham Moles, que trabalhavam na área de informática e escreveram sobre a teoria da informação. Tudo aquilo caiu em desuso. $\mathrm{O}$ tal paradigma da comunicação desapareceu. Primeiro, por que era impossível definir uma disciplina específica a partir do conceito de informação; segundo, o que se entendia por informação era algo sem conteúdo. Uma informação, para ser transmitida, deveria ser decodificada em bits, após esta operação, que reduzia a voz, a imagem, a escrita, à um padrão comum, ela poderia ser trocada entre as máquinas e entre os homens. O problema é que o universo da comunicação social está repleto de conteúdo, de símbolos. O objetivo dos meios é justamente transmitir esses conteúdos, e não apenas bits. Uma telenovela não é a somatória de sinais informáticos. Talvez uma "teoria" deste tipo possa funcionar para os engenheiros, mas dificilmente ela daria conta das relações sociais. No caso do meio ambiente, eu procuro seguir os debates através de meus colegas da Unicamp, também por que me interesso pelo assunto. Mas as dúvidas novamente me assaltam. Existiu no passado um debate a respeito de uma eventual Teoria da Cultura, que atualmente emerge no campo dos Estudos Culturais. Alguns antropólogos acreditavam ser possível delimitar uma esfera da sociedade, a cultura, e considerá-la como um objeto singular, portanto passível de constituir uma disciplina. Não deu certo. Como dizia a escola antropológica britânica, criticando esta ambição dos antropólogos culturalistas norteamericanos: para que isso pudesse acontecer a cultura deveria ser retirada da economia e das relações sociais. Por isso acredito que não exista uma epistemologia dos Estudos Culturais, embora, enquanto área de conhecimento, nela muitas coisas interessantes possam ser realizadas. Gostaria que vocês não entendessem o meu ceticismo como a impossibilidade da estruturação de áreas, nem do saber. Quis apenas observar que as exigências de ordem epistemológicas não são homólogas a criação de zonas interdisciplinares. 


\section{Rosa Maria Feiteiro Cavalari}

Em absoluto, não é essa a idéia e...

\section{Renato Ortiz}

Por isso desconfio daquela história da complexidade, trabalhada por Edgar Morin, ela me parece demasiadamente nebulosa.

\section{Rosa Maria Feiteiro Cavalari}

Segundo a minha visão também, são algumas idéias que ficaram bastante fluidas, não é? São afirmações, mas quando a gente tenta se apropriar daquilo, a gente não sente muito a substância.

\section{Renato Ortiz}

Sim, com pouca densidade conceitual. O debate torna-se muito genérico, circular. Ele se afasta do campo epistemológico e adquire uma feição ética. O que é um contra-senso, pois, em princípio, a epistemologia nada teria a ver com ética. São campos distintos. Tenho às vezes a impressão que essas abordagens holísticas, vinculando o conhecimento à prática (cuja mediação é a ética), têm algo de religioso.

\section{Clarice Sumi Kawasaki}

Renato, eu queria buscar algumas pontes de tudo isso que foi falado para a área de educação ambiental. Quando falamos em educação ambiental, nós estamos falando de uma área grande que é a educação. E aí também, eu acho, me desculpem as pessoas da área, os pedagogos da área educacional também buscam uma epistemologia. Eu tenho um pouco de dificuldade de encontrar uma epistemologia para a área educacional.

\section{Renato Ortiz}

Não tem.

\section{Clarice Sumi Kawasaki}

Não tem, não é? E quando se fala em educação ambiental traz-se um dado novo, uma nova qualidade: uma educação ambiental, mas está dentro do campo da educação, eu vejo assim. E quando você traz a qualidade do ambiental, você recupera aquela discussão que já foi mencionada, ao analisar os trabalhos da área, você vê um forte viés das ciências naturais. Há um forte viés... Não sei se é porque a gente está numa comunidade com muitas pessoas das ciências naturais. Mas isso retoma aquela discussão que você mencionou na conferência, do erro e 
do equívoco, ao mesmo tempo há uma demanda muito grande para responder problemas ambientais, relacionados àquela idéia da utilidade, e, de outro lado, se busca essa autonomia, se quer constituir enquanto uma área do saber, não sei se é um campo, mas uma área do saber. Mas quando olho para tudo isso, eu vejo aí muito mais uma área de mediações, não sei se eu poderia falar assim, entre essas várias fontes em que a educação ambiental acaba bebendo. Então nós não vamos buscar uma síntese. Acho que não se busca uma síntese, mas superar alguns dualismos e trabalhar num campo que eu chamo de mediações. Você acha que isso faz sentido?

\section{Renato Ortiz}

Sim, faz sentido. Por isso eu me perguntei anteriormente, por que essa ansiedade em buscar por algo onde ele não se encontra. Agora, é interessante refletir sobre as questões que você levanta; eu perguntaria, por que as pessoas da área de ciências naturais se interessam pelo tema? Por que elas saem dos laboratórios?

\section{Clarice Sumi Kawasaki}

Eu acho que historicamente, não é? Essa área foi...

\section{Renato Ortiz}

Não, mas elas estão saindo dos laboratórios...

\section{Clarice Sumi Kawasaki}

Sim, sim.

\section{Renato Ortiz}

Isso significa que elas não querem se confinar a um espaço que lhes era tradicional; não querem fazer pesquisa sobre o DNA (o que não significa que isso não seja importante). Porém, elas estão insatisfeitas e têm outros interesses. Só que esta insatisfação as projeta numa outra esfera, a das relações sociais. Isso tem um ponto positivo: uma formação anterior, distinta das ciências sociais, lhes permite enxergar alguns elementos que se encontravam à sombra. Mas há também problemas: quando elas adentram a problemática do meio ambiente, elas perdem as certezas das suas disciplinas. Elas caminham num terreno de incertezas e não mais possuem o controle do conhecimento que era um legado da tradição anterior. As coisas ficam mais complicadas, pois a esfera das "humanidades" possui uma outra lógica. Não que o universo das ciências da natureza desconheça os debates e a dúvida, mas a dúvida é trabalhada dentro de 
um espaço bastante controlado. No mundo das ciências sociais outras questões entram em consideração, pois o pesquisador é parte da realidade que ele mesmo busca compreender (daí as infindáveis discussões sobre política; no caso da educação ambiental exista ainda um objetivo a ser atingido: educar levando-se em consideração as questões do meio ambiente). Eu me pergunto se esta dificuldade em tratar as incertezas não se traduz, de alguma maneira, na busca de um fundamento epistemológico. Mesmo em relação às ciências sociais, minha postura é mais de um "realismo temperado", como disse na minha conferência, nem a sociologia nem a antropologia detém o monopólio da interpretação da sociedade. Elas apenas delimitam um lugar específico no qual uma determinada reflexão se materializa, com um grau razoável de controle, dentro dos dilemas que suas fronteiras porosas estabelecem. Não vejo isso como um drama maior. Evidentemente, vocês que estão no interior de um outro campo de pesquisa, ou querem construir um espaço novo de saber, devem perceber isso de uma outra maneira. Agora, retomando a questão da mediação que foi colocada, poderíamos formular a pergunta de uma outra maneira (eu nunca a tinha formulado assim, estou apenas reagindo às questões que me foram feitas). Mas quais seriam as vantagens de uma nova área de conhecimento? Elas existem, qual o seu significado? De maneira genérica eu diria: se este novo espaço de mediação (evito o termo epistemologia) traz um conjunto de questões diferentes e enriquecedoras do conhecimento, isso seria um ganho. Por isso tenho a tendência em dizer que a interdisciplinaridade, para mim, não é um valor em si. Ela é sempre relacional. Diz respeito ao que se define como um espaço específico, mas também na sua relação com outros espaços disciplinares já existentes. A interdisciplinaridade é rica quando acrescenta algo que não pode ser encontrado, ou desenvolvido, em outros lugares.

\section{Clarice Sumi Kawasaki}

Eu acho que ela não precisa se constituir enquanto uma epistemologia, mas ela pode trazer questões epistemológicas próprias.

\section{Renato Ortiz}

Ah, quanto a isso não tenho dúvida.

\section{Clarice Sumi Kawasaki}

Eu acho que é um movimento interessante também. Essa busca de uma certa autonomia e ao mesmo tempo você saber que nunca vai encontrar essa autonomia total. Talvez seja um movimento... 


\section{Renato Ortiz}

É que às vezes tenho a impressão que as pessoas têm dificuldade de trabalhar com a noção de incerteza. Mesmo nas ciências sociais isso acontece. Pessoalmente, não tenho grandes angústias em relação a isso. De qualquer maneira, obrigatoriamente, a esfera das "humanidades" deve lidar com esta dimensão. No meu caso, vim da engenharia, estudei química e física, terminei por desenvolver uma certa consciência em relação ao contraste entre ciências da natureza e ciências sociais. As ciências sociais são históricas e se realizam em contextos determinados. Não existem "leis universais" que regem os fenômenos sociais.

\section{Rosa Maria Feiteiro Cavalari}

O professor usou uma imagem, a de que os biólogos estão saindo dos laboratórios para a sociedade, para discutir essas questões relativas à temática ambiental, etc. Eu queria fazer o caminho inverso, a pergunta é nesse sentido: por que será que são poucos os cientistas sociais e os filósofos que vão pra natureza?

\section{Renato Ortiz}

Para a natureza ou para o laboratório?

\section{Rosa Maria Feiteiro Cavalari}

Não, para a natureza, desculpe. Aí, eles saem do laboratório para ir discutir as questões relativas à natureza, não é? Então, que explicações poderíamos encontrar para o fato de que são poucos os cientistas sociais e os filósofos que têm as questões relativas à natureza e à temática ambiental como objeto de discussão?

\section{Renato Ortiz}

Mas hoje você já tem uma sociologia ambiental, já...

\section{Rosa Maria Feiteiro Cavalari}

Já tem, aumentou muito, mas...

\section{Renato Ortiz}

Não sei, evidentemente não se trata de uma tradição consolidada, o tema é recente, mas a existência de uma sociologia ambiental é concreta.

\section{Rosa Maria Feiteiro Cavalari}

A questão seria só porque o tema é novo ou ainda estaria muito forte a dicotomia natureza e cultura? 


\section{Renato Ortiz}

Talvez, a dicotomia entre natureza e cultura persiste, mas creio que existem outros motivos. Olhando as coisas do ponto de vista das ciências sociais, eu diria que elas têm muito de conservadoras, e por isso têm uma certa resistência em relação às novas problemáticas. Consagra-se, dentro do seu campo de estudo, objetos que são legítimos e menos legítimos. Por exemplo, a discussão sobre o Estado é tradicional, e predomina no pensamento sociológico até hoje. O meio ambiente não é um grande tema cultivado pela herança intelectual. Neste sentido, as ciências sociais encerram, no processo de sua reprodução, um elemento conservador. Isso vale para outras temáticas, como a globalização. Elas também resistiram muito em pensar uma problemática desta envergadura. Porém, a medida que a área ambiental se implanta, a tendência será de desenvolver-se cada vez mais. No caso da UNICAMP, por exemplo, há vários grupos de pesquisa que caminham nessa direção. Não se trata de dizer que ela seria uma área promissora. Não me refiro ao futuro mas ao presente; ela tem crescido tão rapidamente que torna-se necessário estabelecer alguns controles no recrutamento das pessoas (as novas gerações, marcadas por um certo romantismo, estão muito interessadas nas questões ecológicas). Por outro lado, a problemática do meio ambiente se transformou numa questão política mundial. O que drena recursos. Se há uma área que possui recursos, é a do meio ambiente; e isso provavelmente irá continuar.

\section{Rosa Maria Feiteiro Cavalari}

É uma área que está na moda.

\section{Renato Ortiz}

Está na moda. Mas eu usaria o termo "moda", entre aspas, no sentido de ser atual, mas não fugaz; a problemática do meio ambiente veio para ficar. E ela reveste-se de uma dimensão mundial. A circulação na área ambiental é internacional, seus praticantes deslocam-se por todo o planeta, trocam bibliografias, se encontram. Em termos de circulação, ela é muito mais internacionalizada do que as ciências sociais. A agenda ambiental envolve grupos políticos, ONGs, universidades, institutos de pesquisas. Neste sentido, pareceme que o tema irá se legitimar ainda mais, e atrair sociólogos e antropólogos. O mais difícil é os cientistas sociais entrarem nos laboratórios. Somente aqueles que fazem sociologia da ciência percorrem este trajeto.

\section{Clarice Sumi Kawasaki}

Bom, eu acho que já esgotamos, não é? 
Marco Antonio de Almeida

Ainda teria muita coisa ...

Clarice Sumi Kawasaki

Não, esgotar não, mas agradecemos a disponibilidade do prof. Renato. 